\title{
Foliar nitrogen supply enhances the recovery of photosynthetic performance of cold-stressed coffee (Coffea arabica L.) seedlings
}

\author{
R. ACIDRI ${ }^{*}$, Y. SAWAI**, Y. SUGIMOTO ${ }^{* * *}$, D. SASAGAWA*, T. MASUNAGA*, S. YAMAMOTO\#", \\ and E. NISHIHARA ${ }^{\# \#,+}$
}

The United Graduate School of Agricultural Sciences, Tottori University, 4-101 Koyama-cho Minami, Tottori-shi, Tottori 680-8553, Japan*

Sawai Coffee Limited, 278-6 Takenouchi danchi, Sakaiminato-shi, Tottori 648-0046, Japan **

Tottori Institute of Industrial Technology, 2032-3 Nakano-cho, Sakaiminato-shi, Tottori 684-0041, Japan***

Faculty of Soil Eco-engineering and Plant Nutrition, Shimane University, 1060 Nishikawatsucho, Matsue-shi, Shimane 690-8504, Japan ${ }^{\#}$

Faculty of Agriculture, Tottori University, 4-101 Koyama-cho Minami, Tottori-shi, Tottori 680-8553, Japan \#\#

\begin{abstract}
Cold-stressed leaves possess an elevated risk of photodamage due to an inefficient photosynthetic apparatus during winter conditions. Recovery of cold-stressed coffee seedlings treated with different concentrations of nitrogen applied as foliar urea sprays [control (0), 5, 10, 20, and $40 \mathrm{mM}$ ], was investigated under optimum growth chamber conditions $\left(25 / 20^{\circ} \mathrm{C}\right)$ for three months. Concentrations of nitrogen and photosynthetic pigments in the leaves increased with increasing concentration of the foliar sprays up to $20 \mathrm{mM}$. This was accompanied with a recovery of the photosynthetic apparatus and increased net carbon assimilation rate. In addition, 10 and $20 \mathrm{mM}$-treated plants also had the highest maximal efficiency of PSII compared to their lower or higher nitrogen concentration treated counterparts. Conversely, these plants contained lower concentrations of 5-caffeoylquinic acid, mangiferin, trigonelline, and caffeine than control plants. We concluded therefore that foliar sprays of the appropriate nitrogen concentration were adequate for recuperating the photosynthetic apparatus and improved the photosynthetic performance of the cold-stressed coffee seedlings.
\end{abstract}

Additional key words: alkaloids; chlorophyll fluorescence; phenolic compounds; photochemical efficiency.

\section{Introduction}

Coffee (Coffea spp.) evolved as an understorey shrub species in the tropical rainforest of the mainland Africa and the island of Madagascar under moderate light and temperature conditions (Charrier and Berthaud 1985). Due to its economic value, however, coffee cultivation has expanded to various geographical zones with more severe seasonal climatic conditions and fluctuations such as low night temperatures and high light intensity during winter seasons in Brazil, which is the largest coffee producing country globally (DaMatta and Ramalho 2006). The ability of the coffee plants to adapt to such adverse conditions is owed to the plasticity of its photosynthetic apparatus and a number of photoprotection mechanisms (Chaves et al. 2008, Matos et al. 2009, Fortunato et al. 2010, Ramalho et al. 2014). Nevertheless, the typical low nonfreezing temperatures (between 18 and $4^{\circ} \mathrm{C}$ ) during winter conditions even in $C$. arabica, which is a seemingly more cold-tolerant species, result in diminished vegetative growth as a result of low photosynthetic productivity instigated by both biochemical and diffusivity limitations (DaMatta et al. 1997, Ramalho et al. 2003, 2014).

Low nonfreezing temperatures can cause significant degradation of chlorophyll (Chl) pigments and breakdown of the photosynthetic apparatus (Adams et al. 2004). This is instigated by low photosynthetic efficiency that leads to overproduction of reactive oxygen species (ROS) (Mittler 2002, Asada 2006). ROS in chloroplasts are produced as a result of photoinhibition caused by excess excitation energy in the photosynthetic apparatus (Asada 1999, DaMatta 2004, del Río et al. 2006, Demmig-Adams and Adams 2006). Plants are equipped with an elaborated ROS defence mechanism, which is comprised of both

\footnotetext{
Received 16 March 2020, accepted 1 June 2020.

${ }^{+}$Corresponding author; phone: +81-857-31-5385, e-mail: nishihar@tottori-u.ac.jp

Abbreviations: 5-CQA - 5-caffeoylquinic acid; $\mathrm{CAF}$ - caffeine; Car - carotenoids; $C_{\mathrm{i}} / C_{\mathrm{a}}$ - intercellular to ambient $\mathrm{CO}_{2}$ concentration; $\mathrm{DM}$ - dry mass; $E$ - transpiration rate; $\mathrm{F}_{\mathrm{v}} / \mathrm{F}_{0}$ - potential maximal quantum yield of PSII photochemistry in dark-adapted state; $\mathrm{F}_{\mathrm{v}}{ }^{\prime} / \mathrm{F}_{0}{ }^{\prime}-$ potential maximal quantum yield of PSII photochemistry in light-adapted state; $\mathrm{F}_{\mathrm{v}} / \mathrm{F}_{\mathrm{m}}$ - maximal quantum yield of PSII photochemistry in dark-adapted state; $\mathrm{F}_{\mathrm{v}}{ }^{\prime} \mathrm{F}_{\mathrm{m}}{ }^{\prime}$ - maximal quantum yield of PSII photochemistry in light-adapted state; $g_{\mathrm{s}}$ - stomatal conductance; HPLC - high performance liquid chromatography; NPQ - nonphotochemical quenching coefficient; $P_{\mathrm{N}}-$ net $\mathrm{CO}_{2}$ assimilation rate; $\mathrm{q}_{\mathrm{L}}$ - proportion of PSII open centres; $\mathrm{q}_{\mathrm{N}}$ - fluorescence quenching; $\mathrm{q}_{\mathrm{P}}$ - photochemical quenching coefficient; ROS - reactive oxygen species; $\mathrm{WUE}_{\mathrm{i}}-$ intrinsic water-use efficiency $\left(P_{\mathrm{N}} / g_{\mathrm{s}}\right), \Phi_{\mathrm{PSII}}-$ quantum yield of PSII photochemistry.
} 
enzymatic and nonenzymatic antioxidant systems (Logan et al. 2006, Fortunato et al. 2010). Antioxidant enzymes such as superoxide dismutase catalyse the breakdown of superoxide $\left(\mathrm{O}_{2}{ }^{--}\right)$to hydrogen peroxide $\left(\mathrm{H}_{2} \mathrm{O}_{2}\right)$. Consequently, the $\mathrm{H}_{2} \mathrm{O}_{2}$ is neutralized by catalase and ascorbate peroxidase (Asada 1999). In addition, a number of low molecular mass compounds including both lipophilic and hydrophilic compounds have been characterised as antioxidant scavengers (Das and Roychoudhury 2014). Recently, both alkaloids and phenolic compounds have been implicated in ROS scavenging in coffee plants during oxidative stress conditions (Ramalho et al. 2018). Profound systematic accumulations of high amounts of alkaloids such as caffeine and trigonelline together with phenolic compounds such as chlorogenic acids and mangiferin have been reported in all the cells of the young leaf blades in sun-grown plants compared to their shade counterparts (Campa et al. 2012, 2017). The surge in these secondary metabolites provides the evidence for their role in defence against ROS that are produced in conditions of excess excitation energy to which either the coffee plants is not usually adapted or instigated by abiotic stress conditions. Moreover, because of a repressed enzymatic antioxidant system during cold stress conditions, coffee plants rely on the nonenzymatic antioxidant scavengers for restoration of ROS to homeostatic conditions (Ramalho et al. 2018, Acidri et al. 2020a).

The inherent inability of the rapid remobilization of nitrogen on resumption of favourable temperatures further causes oxidative stress due to a mismatch between biochemical and diffusivity aspects of photosynthesis (DaMatta et al. 1999, Pompelli et al. 2010). Nevertheless, adequate nitrogen supply such as irrigating with $250 \mathrm{~mL}$ containing $23 \mathrm{mM} \mathrm{N}$ every after two weeks for $45 \mathrm{~d}$ has been reported to improve photosynthesis and overall metabolism of coffee plants during winter conditions and also in the growing season during the summer (Ramalho et al. 2000, DaMatta et al. 2002, Carelli et al. 2006, Pompelli et al. 2010, Bote et al. 2018). In addition, nitrogen (nutrition) has also been reported to facilitate the recovery of plants such as rice after exposure to low temperatures (Liu et al. 2019). The use of foliar fertilizers such as urea as a corrective relief for physiological stress is commended for its efficiency and instantaneous assimilation into plant tissues compared to conventional nitrogen application in the soil normally used in coffee production (Gray and Akin 1984, Carelli et al. 2006, Bhuyan et al. 2012, Oad et al. 2018). Soil fertilization generally requires high application rates that result into $\mathrm{NO}_{\mathrm{x}}$ diminution by soil bacteria, which lead to greenhouse gas production (Shepherd et al. 1991). On the other hand, the application rates during foliar fertilization are normally lower with no risk of $\mathrm{NO}_{\mathrm{x}}$ diminution while inducing quick responses in plants (Fageria et al. 2009). Nevertheless, foliar fertilization comes together with challenges that might arise when toxic concentration levels of foliar sprays are applied causing burns and cell mortality (Krogmeier et al. 1989). Moreover, the effect of foliar urea sprays of varying nitrogen concentrations on the recovery of the photosynthetic apparatus, together with several gas exchange and PSII chlorophyll fluorescence parameters as well as the content of selected secondary metabolites in coffee leaves remain unknown. We anticipated that an appropriate concentration of nitrogen applied as foliar urea sprays would improve the biochemical composition resulting into the recovery of the photosynthetic efficiency of the previously cold-stressed coffee plants.

This hypothesis was tested by measuring the changes in gas exchange and associated chlorophyll fluorescence parameters of the coffee plants treated with serial concentrations of nitrogen applied as foliar urea sprays. In addition, the contents of photosynthetic pigments and selected leaf alkaloid and phenolic compounds in coffee leaves were analysed.

\section{Materials and methods}

Plant material and growing conditions: The experiment was conducted between August 2017 and December 2018 at Tottori University $\left(35^{\circ} 30^{\prime} 32.39^{\prime \prime} \mathrm{N}, 134^{\circ} 10^{\prime} 10.80^{\prime \prime} \mathrm{E}\right.$; $20 \mathrm{~m}$ a.s.1.) in Japan. C. arabica L. seeds imported from Bali, Indonesia were germinated by soaking them in running water for $3 \mathrm{~d}$ and thereafter transferred to an incubator on a paper towel. Germination occurred in the dark at $30^{\circ} \mathrm{C}$ in $14 \mathrm{~d}$ (Gebreselassie et al. 2010). After sprouting, each seedling was transplanted into a $10 \times 10 \mathrm{~cm}$ (length $\times$ diameter) pot containing a mixture of peat moss, perlite, and humus at a ratio of $5: 3: 2$, respectively. The seedlings were raised under shade provided by black cheesecloth in a vinyl-house from the summer season (August 2017) with an irrigation regime of $5 \mathrm{~mL}$ of half strength nutrient solution applied every other day. The nutrient solution was prepared according to Hoagland and Arnon (1950) with a few modifications. The concentration of the nutrient solution was in $\mathrm{mmol} \mathrm{L}^{-1}$ : $2.9 \mathrm{~N}-\mathrm{NO}_{3}^{-}$, $0.5 \mathrm{~N}-\mathrm{NH}_{4}^{+}, 0.05 \mathrm{P}-\mathrm{H}_{2} \mathrm{PO}_{4}^{-}, 1.2 \mathrm{Ca}^{2+}, 0.3 \mathrm{Mg}^{2+}, 0.4 \mathrm{~S}-$ $\mathrm{SO}_{4}{ }^{2-}$; and in $\mu \mathrm{mol} \mathrm{L}{ }^{-1}: 17.5 \mathrm{Fe}$ (III) EDTA, $0.4 \mathrm{Cu}, 0.8 \mathrm{Zn}$, $3 \mathrm{Mn}, 9 \mathrm{~B}$, and $0.05 \mathrm{Mo}$. The coffee seedlings were cultivated until the onset of winter season (December 2018) under naturally fluctuating environmental conditions (Fig. 1). The average minimum winter temperatures caused visual signs of cold stress including stunted growth and yellowing of the leaves (Fig. 2).

For experimentation, visually uniform cold-stressed seedlings were transferred into the growth chamber and grown under PPFD of $250 \mu \mathrm{mol} \mathrm{m}^{-2} \mathrm{~s}^{-1}$ provided by white luminescent lamps at a 12 -h photoperiod, temperature of $25 / 20^{\circ} \mathrm{C}$, (day and night, respectively), and a $70 \%$ relative humidity. Five treatments were thereafter established by adjusting the concentration of nitrogen applied as foliar sprays in form of urea. The treatments included: Control (0), 5, 10, 20, and $40 \mathrm{mM}$ N. Isopropyl alcohol (Kao Global Chemicals, Tokyo, Japan) solution (1\%) was used as a surfactant in all the treatments. The sprays were administered just before darkness, one time per week for $90 \mathrm{~d}$ on the whole shoot until runoff on the leaves occurred. The sprays were applied on all the experimental units at once using a volume of $20 \mathrm{~mL}$ of the urea solution per treatment. All the seedlings were continuously irrigated with the previously described Hoagland solution but without nitrogen throughout the experimental term. 


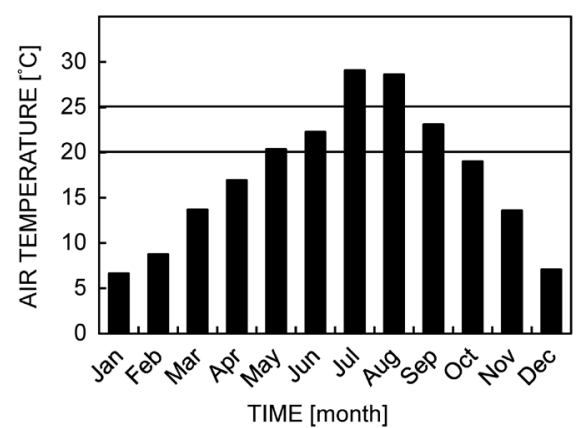

Fig. 1. Time-course changes in the monthly average of the ambient temperatures during a one-year period in the naturally conditioned greenhouse at Tottori University, western Japan. Horizontal lines indicate the adequate minimum and maximum temperatures for ideal cultivation of Coffea arabica L. according to Partelli et al. (2009).

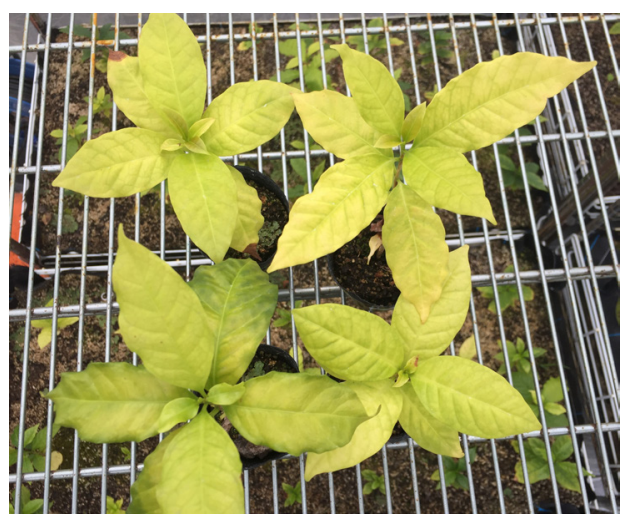

Fig. 2. Coffee seedlings exhibiting visual signs such as yellowing of the leaves induced by cold stress conditions.

Gas exchange and Chl fluorescence: Photosynthetic responses and $\mathrm{Chl}$ fluorescence parameters were measured on fully expanded leaves of the first pair using $L i-6400$ $X T$ open gas-exchange system (LICOR Biosciences, Lincoln, NE, USA). The system was checked for leaks and calibrated each time before the measurements were taken. Gas exchange and fluorescence measurements at the light-adapted state were done after the 6-h illumination at a $400 \mathrm{ppm} \mathrm{CO}_{2}$ concentration and PPFD of $500 \mu \mathrm{mol}$ $\mathrm{m}^{-2} \mathrm{~s}^{-1}$ (10\% blue) according to Pompelli et al. (2010). The dark-adapted state fluorescence parameters were measured $6 \mathrm{~h}$ after the onset of darkness using the same system. Nonphotochemical quenching, proportion of open PSII centres and the maximum quantum efficiency of the PSII photochemistry for both the dark-adapted and lightadapted states were calculated according to Murchie and Lawson (2013).

\section{Biochemical analysis}

Sample preparation: At the end of the experiment, fully expanded leaves corresponding to first and the second pair from the top were collected after 6-h illumination (corresponding to midday) for biochemical analysis. The leaves were thoroughly washed and rinsed with distilled water to remove surface contaminations. The samples were thereafter immediately flash frozen in liquid nitrogen and stored under $-80^{\circ} \mathrm{C}$ for further analysis. For all the assays, the samples were freeze-dried (Eyela DRC 1000FDU 1110, Tokyo, Japan) and thereafter milled into a fine powder using a blender (Wonder blender, Osaka, Japan).

Total nitrogen in the leaf samples was measured using an organic elemental analyser (CN corder JM1000CN, Tokyo, Japan).

Photosynthetic pigments extraction and quantification: The concentrations of Chls and carotenoids were determined according to Porra et al. (1989) with a few modifications. Extraction was made from the freeze-dried powder using $80 \%$ chilled acetone in $50-\mathrm{mL}$ Falcon tubes (Thermo Fisher Scientific, Massachusetts, USA) in the dark. The mixture was sonicated in ice-cold water bath in three cycles of $15 \mathrm{~min}$ each and centrifuged at 29,300 $\times \mathrm{g}$ at a temperature of $4^{\circ} \mathrm{C}$ (Hitachi high-speed refrigerated centrifuge CR21N, Hitachi Koki Co. Ltd., Tokyo, Japan). Extraction was repeated until the green residue turned white. All the extracts were pooled together for analysis in a known volume of the solution. Absorbance was read using a spectrophotometer (Hitachi ratio beam spectrophotometer, U-5100, Japan). Chls and carotenoid concentrations were calculated using equations developed by Porra et al. (1989) and Lichtenthaler and Buschmann (2001), respectively.

HPLC quantification of the selected metabolites: Alkaloids and phenolic compounds were analysed according to Acidri et al. (2020b). The analytes were determined simultaneously using a high-performance liquid chromatography (HPLC) system equipped with a UV detector at a wavelength of $270 \mathrm{~nm}$ (Hitachi L-2490, Hitachi, Tokyo, Japan) from a $10-\mu \mathrm{L}$ sample extract. Separation of the analytes was performed on a TSKgel ODS-100 C18 column $(5-\mu \mathrm{m}$ particles size, $4.6 \times 150 \mathrm{~mm})$ in a thermostatic oven at a temperature of $40^{\circ} \mathrm{C}$ (Sigma Aldrich, Tokyo, Japan) with a binary phase mobile gradient at a total flow rate of $0.4 \mathrm{~mL} \mathrm{~min}-1$. The mobile phase consisted of two filtered (0.22 $\mu \mathrm{m}$ Millipore), sonicated and degassed solvents A (methanol, 100\%) and $\mathrm{B}$ (acetic acid: $\mathrm{H}_{2} \mathrm{O}, 98: 2, \mathrm{v} / \mathrm{v}$ ) with linear evolution of the gradient profile according to a set elution program. Calibration curves were obtained from three replicate points for the standard compounds (trigonelline, 5-CQA, caffeine, and mangiferin). The selected compounds were reported to increase in the leaves of coffee plants during oxidative stress conditions (Campa et al. 2017, Ramalho et al. 2018, Acidri et al. 2020a). Each sample or standard was eluted for 25 min followed by idling for $20 \mathrm{~min}$ interval before proceeding to the next. Each analyte from the samples was then identified by peak position and thereafter quantified by peak area measurement using regression equations developed from calibration curves for the standard compounds. All the analytical standards and the organic solvents used were of HPLC grade (Sigma Aldrich, Tokyo, Japan). 
Statistical analyses: Experimental data were analysed using a one-way analysis of variance (ANOVA) by comparing variation in the parameters among the treatments. Comparison for statistical differences were made using the Newman-Keuls's test at $p \leq 0.05$. Normality tests were done using the Kolmogorov-Smirnov's test and data transformed accordingly to attain a normal distribution whenever necessary. All the statistical analyses were done using Stata 12.0 statistics and data analysis program (Stata Corp., Texas, USA). Data are expressed as means \pm SD, $n \geq 3$.

\section{Results}

Total nitrogen content in the leaves increased considerably with increasing concentration of the urea foliar sprays (Table 1). Compared to control treatment plants, the concentration of nitrogen in the leaves increased with increasing concentration of nitrogen in the foliar sprays for 5,10 , and $20 \mathrm{mM}$ treatments. However, despite showing no statistical significance, a further increase of $100 \%$ in the concentration of foliar nitrogen supply to $40 \mathrm{mM}$ caused a $3.5 \%$ decline in the concentration of leaf nitrogen compared to the preceding $(20 \mathrm{mM})$ treatment.

Photosynthetic pigments: Variation in the concentration of Chls and carotenoids is indicated in Table 1. The concentrations of the respective Chl components $a$ and $b$ and their corresponding total $(a+b)$ were the least in the leaves of control treatment plants. These increased with the increasing concentration of the nitrogen supply in the treatments. This increasing trend climaxed in the $20 \mathrm{mM}$ treatment plants while further increase in the concentration of the foliar sprays to $40 \mathrm{mM}$ caused a consistent decline of $16.5,13.7$, and $15.9 \%$ in the concentrations of Chl $a, b$ and their corresponding total $(a+b)$, respectively.

Although not significantly different, the concentration of the total carotenoids determined as a sum of xanthophylls and beta carotene $(x+c)$, also showed a similar trend to that of Chls in variation amongst the treatments. Total carotenoids were the least in the control treatment plants and thereafter increased in the 5, 10, and $20 \mathrm{mM}$ treated plants. Similarly, a further increase to $40 \mathrm{mM}$ of foliar sprays instigated a decline in the concentration of total carotenoids.

The ratio of $\mathrm{Chl} a / b$ was the lowest in the control plants and increased with the increasing nitrogen concentration in the 5, 10, and $20 \mathrm{mM}$ treated plants, respectively. Thereafter, the ratio of the $\mathrm{Chl} a / b$ indicated a slight decline despite an increase in the concentration of foliarly applied nitrogen in the $40 \mathrm{mM}$ treatment. On the other hand, although the ratio of total chlorophylls to total carotenoids was the least in the control plants, it was the highest in $5 \mathrm{mM}$ treatment plants and thereafter consistently declining despite the increase in the concentration of nitrogen treatment $(10,20$, and $40 \mathrm{mM})$. Nevertheless, the ratios of the concentration of the pigments to that of nitrogen in the leaves was generally constant amongst that treatments despite slight declines in the respective ratios in the $40 \mathrm{mM}$ treatment plants compared to the rest of the plants.

Taken together, the current results generally indicated that foliar application of nitrogen up to $20 \mathrm{mM}$ improved the nitrogen status in the leaves of the coffee plants compared with control counterparts. This was accompanied by an increase in the accumulation of the photosynthetic pigments especially Chl. On the other, a further increase in the concentration of nitrogen in the urea treatments caused low concentrations of both leaf nitrogen and photosynthetic pigment.

Improved gas exchange and $\mathbf{C h l}$ fluorescence: The net $\mathrm{CO}_{2}$ assimilation rate $\left(P_{\mathrm{N}}\right)$ was the lowest in the control plants with $5.9 \mu \mathrm{mol}\left(\mathrm{CO}_{2}\right) \mathrm{m}^{-2} \mathrm{~s}^{-1}$, gradually increasing

Table 1. Effect of foliar nitrogen supply on the concentrations of leaf total nitrogen (N), chlorophylls $a$ and $b$ (Chl $a$ and Chl $b$, respectively), total chlorophyll [Chl $(a+b)$ ], total carotenoids [Car $(x+c)$ ], ratios of $\mathrm{Chl} a$ to $b(\mathrm{Chl} a / b)$, chlorophyll to carotenoids $(\mathrm{Chl} / \mathrm{Car})$, chlorophyll $a$ to nitrogen $(\mathrm{Chl} a / \mathrm{N})$, chlorophyll $b$ to $\mathrm{N}(\mathrm{Chl} b / \mathrm{N})$, total chlorophyll to $\mathrm{N} \mathrm{Chl} / \mathrm{N})$ and that of total carotenoids to $\mathrm{N}(\mathrm{Car} / \mathrm{N})$ in the leaves of coffee seedlings recovering from cold stress treated with different concentrations of foliar nitrogen in form of urea weekly for three months in a growth chamber. Different letters in a row denote significant differences between the treatment means $(p<0.05$, Newman-Keuls's test). Data are expressed as means $\pm \operatorname{SD}(n=4)$.

\begin{tabular}{|c|c|c|c|c|c|}
\hline \multirow[t]{2}{*}{ Parameter } & \multicolumn{5}{|c|}{ Foliar nitrogen supply [mM] } \\
\hline & 0 & 5 & 10 & 20 & 40 \\
\hline Total $\mathrm{N}\left[\mathrm{mg} \mathrm{g}^{-1}(\mathrm{DM})\right]$ & $19.3 \pm 4.3^{\mathrm{c}}$ & $25.3 \pm 3.0^{\mathrm{b}}$ & $29.4 \pm 2.6^{\mathrm{ab}}$ & $34.4 \pm 1.0^{\mathrm{a}}$ & $33.2 \pm 3.8^{\mathrm{a}}$ \\
\hline Chl $a\left[\mathrm{mg} \mathrm{g}^{-1}(\mathrm{DM})\right]$ & $3.77 \pm 0.59^{b}$ & $5.30 \pm 1.00^{\mathrm{ab}}$ & $6.58 \pm 1.60^{\mathrm{a}}$ & $6.84 \pm 2.07^{\mathrm{a}}$ & $5.71 \pm 0.74^{\mathrm{ab}}$ \\
\hline $\mathrm{Chl} b\left[\mathrm{mg} \mathrm{g}^{-1}(\mathrm{DM})\right]$ & $1.47 \pm 0.19^{b}$ & $1.92 \pm 0.38^{\mathrm{ab}}$ & $2.30 \pm 0.44^{\mathrm{a}}$ & $2.34 \pm 0.59^{\mathrm{a}}$ & $2.02 \pm 0.19^{\mathrm{ab}}$ \\
\hline $\operatorname{Chl}(a+b)\left[\mathrm{mg} \mathrm{g}^{-1}(\mathrm{DM})\right]$ & $5.25 \pm 0.78^{\mathrm{b}}$ & $7.23 \pm 1.38^{\mathrm{ab}}$ & $8.88 \pm 2.04^{\mathrm{a}}$ & $9.18 \pm 2.66^{\mathrm{a}}$ & $7.72 \pm 0.93^{\mathrm{ab}}$ \\
\hline $\operatorname{Car}(x+c)\left[\mathrm{mg} \mathrm{g}^{-1}(\mathrm{DM})\right]$ & $1.03 \pm 0.23^{\mathrm{a}}$ & $1.13 \pm 0.18^{\mathrm{a}}$ & $1.52 \pm 0.32^{\mathrm{a}}$ & $1.59 \pm 0.37^{\mathrm{a}}$ & $1.42 \pm 0.14^{\mathrm{a}}$ \\
\hline Chl $a / b$ & $2.55 \pm 0.08^{\mathrm{b}}$ & $2.76 \pm 0.11^{\mathrm{a}}$ & $2.84 \pm 0.19^{\mathrm{a}}$ & $2.90 \pm 0.14^{\mathrm{a}}$ & $2.82 \pm 0.10^{\mathrm{a}}$ \\
\hline $\mathrm{Chl} / \mathrm{Car}$ & $5.20 \pm 0.81^{\mathrm{b}}$ & $6.35 \pm 0.35^{\mathrm{a}}$ & $5.81 \pm 0.16^{\mathrm{ab}}$ & $5.72 \pm 0.56^{\mathrm{ab}}$ & $5.43 \pm 0.18^{\mathrm{b}}$ \\
\hline $\mathrm{Chl} a / \mathrm{N}$ & $0.20 \pm 0.06^{\mathrm{a}}$ & $0.21 \pm 0.04^{\mathrm{a}}$ & $0.22 \pm 0.05^{\mathrm{a}}$ & $0.20 \pm 0.06^{\mathrm{a}}$ & $0.17 \pm 0.03^{\mathrm{a}}$ \\
\hline $\mathrm{Chl} b / \mathrm{N}$ & $0.08 \pm 0.02^{\mathrm{a}}$ & $0.08 \pm 0.01^{\mathrm{a}}$ & $0.08 \pm 0.01^{\mathrm{a}}$ & $0.07 \pm 0.02^{\mathrm{a}}$ & $0.06 \pm 0.01^{\mathrm{a}}$ \\
\hline $\mathrm{Chl} / \mathrm{N}$ & $0.28 \pm 0.08^{\mathrm{a}}$ & $0.29 \pm 0.06^{\mathrm{a}}$ & $0.30 \pm 0.06^{\mathrm{a}}$ & $0.27 \pm 0.08^{\mathrm{a}}$ & $0.23 \pm 0.04^{\mathrm{a}}$ \\
\hline $\mathrm{Car} / \mathrm{N}$ & $0.06 \pm 0.02^{\mathrm{a}}$ & $0.05 \pm 0.01^{\mathrm{a}}$ & $0.05 \pm 0.01^{\mathrm{a}}$ & $0.05 \pm 0.01^{\mathrm{a}}$ & $0.04 \pm 0.01^{\mathrm{a}}$ \\
\hline
\end{tabular}


with the increase in the concentration of the foliarly applied nitrogen in the treatments and peaking in the plants treated with $10 \mathrm{mM}$ nitrogen at $8.3 \mu \mathrm{mol}\left(\mathrm{CO}_{2}\right) \mathrm{m}^{-2} \mathrm{~s}^{-1}$ (Fig. $3 A$ ). Further increase in the concentration of nitrogen in the treatments was, however, associated with a steady decline in $P_{\mathrm{N}}$ from 8.3 to 6.7 and $7.2 \mu \mathrm{mol}\left(\mathrm{CO}_{2}\right) \mathrm{m}^{-2} \mathrm{~s}^{-1}$ in the 20 , and $40 \mathrm{mM}$ nitrogen-treated plants respectively. Similarly, although stomatal conductance $\left(g_{\mathrm{s}}\right)$ was not statistically different between the treatments (Fig. 3B), $g_{\text {s }}$ was the lowest in the control and $40 \mathrm{mM}$ plant with 51.4 and $50.3 \mu \mathrm{mol}\left(\mathrm{H}_{2} \mathrm{O}\right) \mathrm{m}^{-2} \mathrm{~s}^{-1}$ and the highest in the 10 and $20 \mathrm{mM}$ plants at 62.6 and $63.3 \mu \mathrm{mol}\left(\mathrm{H}_{2} \mathrm{O}\right) \mathrm{m}^{-2} \mathrm{~s}^{-1}$, while plants under $5 \mathrm{mM}$ exhibited $g_{\mathrm{s}}$ at $54.3 \mu \mathrm{mol}\left(\mathrm{H}_{2} \mathrm{O}\right) \mathrm{m}^{-2} \mathrm{~s}^{-1}$.

Intrinsic water-use efficiency $\left(\mathrm{WUE}_{\mathrm{i}}\right)$, estimated as a ratio of net $\mathrm{CO}_{2}$ assimilation rate to stomatal conductance $\left(P_{\mathrm{N}} / g_{\mathrm{s}}\right)$, was also low in the control and $40 \mathrm{mM}$ plants at 0.12 for the two treatments. Plants under $5 \mathrm{mM}$ had

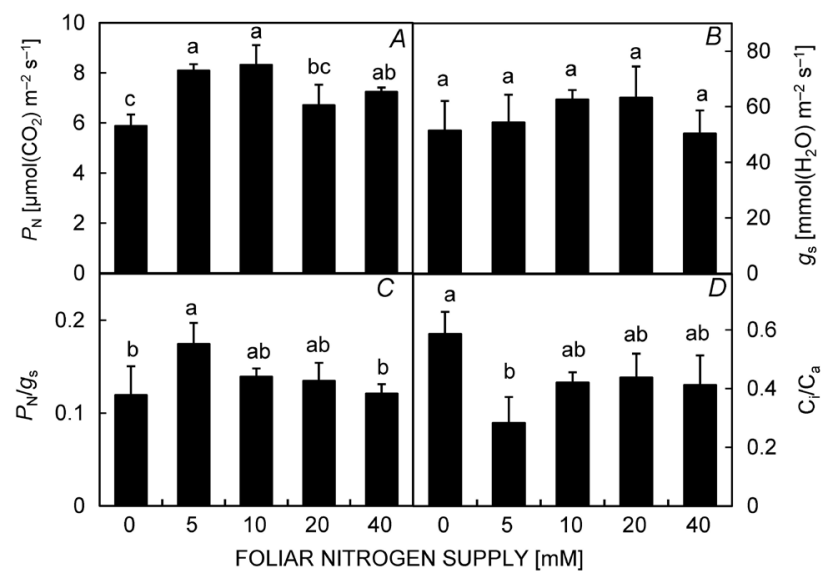

Fig. 3. Effects of foliar nitrogen supply on net photosynthetic rate $\left(P_{\mathrm{N}}\right)(A)$, stomatal conductance $\left(g_{\mathrm{s}}\right)(B)$, intrinsic water-use efficiency $\left(P_{\mathrm{N}} / g_{\mathrm{s}}\right)(C)$, and the ratio of internal to ambient $\mathrm{CO}_{2}$ concentration $\left(C_{\mathrm{i}} / C_{\mathrm{a}}\right)(D)$. Nitrogen was applied as weekly foliar sprays in the form of urea on previously cold-stressed plants for three months in a growth chamber $\left(25 / 20^{\circ} \mathrm{C}\right.$, day/night, respectively). Gas-exchange measurements were done at $6^{\text {th }}$ hour of lighting. Different letters denote significant differences in the treatment means at $p<0.05$, Newman-Keuls's test (foliar nitrogen effect). Error bars represent SD of the mean $(n=3)$. significantly higher $\mathrm{WUE}_{\mathrm{i}}$ of 0.17 , whereas 10 , and $20 \mathrm{mM}$ plants indicated moderate values of 0.14 and 0.13 , respectively (Fig. $3 C$ ). In contrast, the ratio of internal to ambient $\mathrm{CO}_{2}$ concentration $\left(C_{\mathrm{i}} / C_{\mathrm{a}}\right)$ was significantly higher for the control plants at 0.59 , whereas nitrogen treatments had relatively lower $C_{\mathrm{i}} / C_{\mathrm{a}}$ of $0.28,0.42,0.44$, and 0.41 for plants under $5,10,20$, and $40 \mathrm{mM}$, respectively (Fig. 3D). The current results suggest therefore that nitrogen supply especially at lower application levels improved the rates of gas exchange in the leaves of the coffee plants. This was accompanied by a higher rate of $\mathrm{CO}_{2}$ assimilation and hence resulting into low $C_{\mathrm{i}} / C_{\mathrm{a}}$ in the treated compared with control plants.

The improved gas exchange in the treated plants was also accompanied with improved PSII photochemistry (Table 2). Despite showing no significant differences between the treatments, both the PSII photochemical efficiency $\left(\Phi_{\text {PSII }}\right)$ and the electron transport rate $(E T R)$ were the highest in plants under $10 \mathrm{mM}$ treatment. On the other hand, both control and $40 \mathrm{mM}$ plants showed the least values of $\Phi_{\text {PSII }}$ and ETR, while plants under 5 and $20 \mathrm{mM}$ treatments exhibited moderate $\Phi_{\mathrm{PSII}}$ values. Similarly, the ETR values for the two treatments (5 and $20 \mathrm{mM}$ ) was moderate when compared to control and $40 \mathrm{mM}$ plants.

Allocation of absorbed PAR to photochemistry indicated a consistent decline in the proportion of photochemical quenching $\left(\mathrm{q}_{\mathrm{p}}\right)$ with the increase in the concentration of the nitrogen in treatments (Table 2). As a consequence, control and $5 \mathrm{mM}$ plants exhibited the highest $\mathrm{q}_{\mathrm{p}}$, which was lowered in the $10 \mathrm{mM}$ plants, whereas 20 and $40 \mathrm{mM}$ showed the least $\mathrm{q}_{\mathrm{P}}$ values. On the other hand, although the nonphotochemical quenching (NPQ) declined in the 5 and $10 \mathrm{mM}$ plants compared with the control plants, a slight increment in NPQ was noticed in the 20 and $40 \mathrm{mM}$ plants (Table 2). The proportion of PAR neither used in photochemistry nor dissipated as heat also known as fluorescence quenching $\left(\mathrm{q}_{\mathrm{N}}\right)$ varied inversely to NPQ (Table 2). $\mathrm{q}_{\mathrm{N}}$ was significantly higher in $5,10,20 \mathrm{mM}$ plants and lower in the control and $40 \mathrm{mM}$ plants. Similarly, more PSII reaction centres $\left(\mathrm{q}_{\mathrm{L}}\right)$ also tended to remain open in plants treated with low concentration of nitrogen in the sprays (Table 2). On the contrary, both control plants

Table 2. Effect of foliar nitrogen supply on the quantum yield of photosystem II photochemistry ( $\left.\Phi_{\text {PSII }}\right)$, electron transfer rate (ETR), photochemical quenching $\left(\mathrm{q}_{\mathrm{P}}\right)$, fluorescence quenching $\left(\mathrm{q}_{\mathrm{N}}\right)$, nonphotochemical quenching (NPQ), and the proportion of PSII open centres $\left(\mathrm{q}_{\mathrm{L}}\right)$ in the leaves of coffee seedlings recovering from cold stress treated with foliar nitrogen weekly for three months in a growth chamber. Different letters in a row denote significant differences between the treatment means $(p<0.05$, Newman-Keuls's test). Data are expressed as means $\pm \mathrm{SD}(n=3)$.

\begin{tabular}{llllll}
\hline Parameter & \multicolumn{4}{l}{ Foliar nitrogen supply $[\mathrm{mM}]$} & \\
& 0 & 5 & 10 & 20 & 40 \\
\hline$\Phi_{\text {PSII }}$ & $0.10 \pm 0.01^{\mathrm{a}}$ & $0.11 \pm 0.01^{\mathrm{a}}$ & $0.12 \pm 0.00^{\mathrm{a}}$ & $0.11 \pm 0.02^{\mathrm{a}}$ & $0.11 \pm 0.01^{\mathrm{a}}$ \\
$\mathrm{ETR}\left[\mu \mathrm{mol} \mathrm{m}^{-2} \mathrm{~s}^{-1}\right]$ & $22.8 \pm 1.93^{\mathrm{a}}$ & $24.3 \pm 3.10^{\mathrm{a}}$ & $25.5 \pm 0.95^{\mathrm{a}}$ & $23.2 \pm 3.94^{\mathrm{a}}$ & $20.2 \pm 2.35^{\mathrm{a}}$ \\
$\mathrm{q}_{\mathrm{P}}$ & $0.23 \pm 0.02^{\mathrm{a}}$ & $0.23 \pm 0.02^{\mathrm{a}}$ & $0.19 \pm 0.02^{\mathrm{a}}$ & $0.17 \pm 0.04^{\mathrm{a}}$ & $0.17 \pm 0.04^{\mathrm{a}}$ \\
$\mathrm{NPQ}$ & $1.39 \pm 0.32^{\mathrm{a}}$ & $1.06 \pm 0.17^{\mathrm{a}}$ & $0.85 \pm 0.21^{\mathrm{a}}$ & $0.87 \pm 0.15^{\mathrm{a}}$ & $1.30 \pm 0.21^{\mathrm{a}}$ \\
$\mathrm{q}_{\mathrm{N}}$ & $1.97 \pm 0.05^{\mathrm{b}}$ & $2.25 \pm 0.07^{\mathrm{a}}$ & $2.45 \pm 0.12^{\mathrm{a}}$ & $2.30 \pm 0.18^{\mathrm{a}}$ & $1.98 \pm 0.13^{\mathrm{b}}$ \\
$\mathrm{q}_{\mathrm{L}}$ & $0.37 \pm 0.03^{\mathrm{a}}$ & $0.40 \pm 0.05^{\mathrm{a}}$ & $0.42 \pm 0.01^{\mathrm{a}}$ & $0.38 \pm 0.05^{\mathrm{a}}$ & $0.35 \pm 0.02^{\mathrm{a}}$ \\
\hline
\end{tabular}


and those treated with high concentrations of nitrogen sustained less open PSII reaction centres.

The maximum quantum efficiency of PSII during the dark-adapted state expressed as $\mathrm{F}_{\mathrm{v}} / \mathrm{F}_{\mathrm{m}}$ and $\mathrm{F}_{\mathrm{v}} / \mathrm{F}_{0}$ (Fig. $4 A, B$ ) and that during the light-adapted state, $\mathrm{F}_{\mathrm{v}}{ }^{\prime} / \mathrm{F}_{\mathrm{m}}{ }^{\prime}$ and $\mathrm{F}_{\mathrm{v}}{ }^{\prime} / \mathrm{F}_{0}{ }^{\prime}$ (Fig. $4 C, D$ ), were the highest for the low concentration nitrogen-treated plants. Moreover, despite varying non-significantly amongst the treatments, $F_{v} / F_{m}$ was the least for both control and $40 \mathrm{mM}$ plants at 0.75 , while the $\mathrm{F}_{\mathrm{v}} / \mathrm{F}_{\mathrm{m}}$ values for the other treatments were 0.77 (Fig. 4A). Similarly, $\mathrm{F}_{\mathrm{v}} / \mathrm{F}_{0}$ was the lowest for control and $40 \mathrm{mM}$ plants at 3.0 for the two treatments while the low-nitrogen treatments exhibited $\mathrm{F}_{\mathrm{v}} / \mathrm{F}_{0}$ values of 3.23 , 3.44 , and 3.26 for 5,10 , and $20 \mathrm{mM}$ plants, respectively (Fig. 4B). The improvement in the maximum quantum

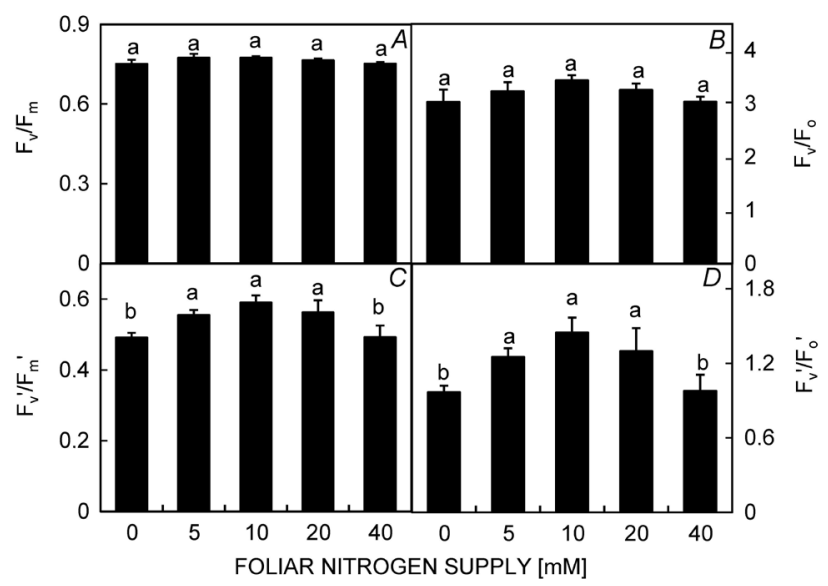

Fig. 4. Effect of foliar nitrogen supply on the ratios of variable to maximum $\left(\mathrm{F}_{\mathrm{v}} / \mathrm{F}_{\mathrm{m}}, \mathrm{F}_{\mathrm{v}}{ }^{\prime} / \mathrm{F}_{\mathrm{m}}{ }^{\prime}\right)(A, C)$, and variable to initial $\left(\mathrm{F}_{\mathrm{v}} / \mathrm{F}_{0}\right.$, $\left.\mathrm{F}_{\mathrm{v}}{ }^{\prime} / \mathrm{F}_{0}{ }^{\prime}\right)(B, D)$ photosystem II maximum efficiency during the dark-adapted $\left(\mathrm{F}_{\mathrm{v}} / \mathrm{F}_{\mathrm{m}}, \mathrm{F}_{\mathrm{v}} / \mathrm{F}_{0}\right)(A, B)$ and the light-adapted $\left(\mathrm{F}_{\mathrm{v}}{ }^{\prime} / \mathrm{F}_{\mathrm{m}}{ }^{\prime}\right.$, $\left.\mathrm{F}_{\mathrm{v}}{ }^{\prime} / \mathrm{F}_{0}{ }^{\prime}\right)(C, D)$ chlorophyll states in the leaves of coffee plants. Nitrogen was applied as weekly foliar sprays in the form of urea on previously cold-stressed plants for three months in a growth chamber $\left(25 / 20^{\circ} \mathrm{C}\right.$, Day/night, respectively). Light-adapted chlorophyll state was done at $6^{\text {th }}$ hour of lighting whereas for dark-adapted state, the plants were measured after $6 \mathrm{~h}$ in total darkness. Different letters denote significant differences in the treatment means at $p<0.05$, Newman-Keuls's test (foliar nitrogen effect). Error bars represent SD of the mean $(n=3)$. efficiency of PSII as a result of adequate nitrogen supply was more visible during the light-adapted state measurements with both control and $40 \mathrm{mM}$ plants indicating significantly lower $\mathrm{F}_{\mathrm{v}}{ }^{\prime} / \mathrm{F}_{\mathrm{m}}{ }^{\prime}$ values of 0.49 , while 5,10 , and $20 \mathrm{mM}$ plants showed $\mathrm{F}_{\mathrm{v}}{ }^{\prime} / \mathrm{F}_{\mathrm{m}}{ }^{\prime}$ values of $0.56,0.59$, and 0.56 , respectively (Fig. $4 C$ ). In addition, $\mathrm{F}_{\mathrm{v}}{ }^{\prime} / \mathrm{F}_{0}{ }^{\prime}$ were also significantly lower in the control and $40 \mathrm{mM}$ plants at 0.97 and 0.98 , while plants under 5,10 , and $20 \mathrm{mM}$ indicated $1.25,1.45$, and 1.30 , respectively (Fig. 4D). The current results suggest therefore that foliar nitrogen at lower concentrations improved the photochemical efficiency of PSII compared with the control plants whereas at the highest concentration $(40 \mathrm{mM})$ caused the decline in the PSII quantum efficiency.

Content of the selected metabolites: Variations in the content of the selected metabolites amongst the treatments are indicated in Table 3. Caffeine showed neither significant differences nor peculiar trend in variation amongst the treatments. Nevertheless, plants under control, 10, and $20 \mathrm{mM}$ treatments contained the highest content of caffeine while plants under 5 and $40 \mathrm{mM}$ treatments contained the least caffeine content, respectively. On the other hand, trigonelline was significantly higher in control plants and lower in $40 \mathrm{mM}$ plants. Plants under 5, 10, and $20 \mathrm{mM}$ treatments contained moderate contents of trigonelline. Similarly, 5-CQA was significantly higher in control plants and lower in plants under $40 \mathrm{mM}$, while plants under 5,10 , and $20 \mathrm{mM}$ treatments had moderate contents of the hydroxycinnamic acid ester, respectively. On the other hand, although mangiferin was not significantly different between the treatments, control plants had the highest content of the xanthonoid phenolic compound with $0.14 \mathrm{mg} \mathrm{g}^{-1}(\mathrm{DM})$, while the content of mangiferin in all the nitrogen treatments was well below $0.10 \mathrm{mg} \mathrm{g}^{-1}(\mathrm{DM})$.

Consequently, the total content of these selected metabolites was significantly higher in control plants and lower in plants under $40 \mathrm{mM}$, while 5, 10, and $20 \mathrm{mM}$ contained median amounts, respectively. Similarly, the ratio of 5-CQA to caffeine despite showing no significant differences in variation between the treatments, was the highest in plants under control and lower in the nitrogentreated plants.

Table 3. Effects of foliar nitrogen supply on the concentrations of caffeine, 5-caffeoylquinic acid, trigonelline, mangiferin, ratio of 5-caffeoylquinic acid to caffeine and the total content of these metabolites in the leaves of coffee seedlings recovering from cold stress treated with foliar nitrogen weekly for three months in a growth chamber. Different letters in a row denote significant differences between the treatment means $(p<0.05$, Newman-Keuls's test). Data are expressed as mean $\pm \operatorname{SD}(n=3)$.

\begin{tabular}{llllll}
\hline \multirow{2}{*}{ Parameter } & \multicolumn{4}{l}{ Foliar nitrogen concentration $[\mathrm{mM}]$} & \\
& 0 & 5 & 10 & 20 & 40 \\
\hline Caffeine $\left[\mathrm{mg} \mathrm{g}^{-1}(\mathrm{DM})\right]$ & $0.99 \pm 0.17^{\mathrm{a}}$ & $0.69 \pm 0.10^{\mathrm{a}}$ & $0.93 \pm 0.11^{\mathrm{a}}$ & $0.94 \pm 0.08^{\mathrm{a}}$ & $0.73 \pm 0.19^{\mathrm{a}}$ \\
Trigonelline $\left[\mathrm{mg} \mathrm{g}^{-1}(\mathrm{DM})\right]$ & $0.61 \pm 0.16^{\mathrm{a}}$ & $0.41 \pm 0.02^{\mathrm{ab}}$ & $0.43 \pm 0.08^{\mathrm{ab}}$ & $0.45 \pm 0.03^{\mathrm{ab}}$ & $0.33 \pm 0.07^{\mathrm{b}}$ \\
5-caffeoylquinic acid $\left[\mathrm{mg} \mathrm{g}^{-1}(\mathrm{DM})\right]$ & $5.89 \pm 1.06^{\mathrm{a}}$ & $3.45 \pm 0.77^{\mathrm{b}}$ & $4.07 \pm 0.71^{\mathrm{ab}}$ & $4.26 \pm 0.16^{\mathrm{ab}}$ & $3.19 \pm 1.21^{\mathrm{b}}$ \\
Mangiferin [mg g $(\mathrm{DM})]$ & $0.14 \pm 0.04^{\mathrm{a}}$ & $0.08 \pm 0.00^{\mathrm{a}}$ & $0.10 \pm 0.02^{\mathrm{a}}$ & $0.09 \pm 0.03^{\mathrm{a}}$ & $0.08 \pm 0.04^{\mathrm{a}}$ \\
Total content [mg g $(\mathrm{DM})]$ & $7.63 \pm 0.93^{\mathrm{a}}$ & $4.63 \pm 0.82^{\mathrm{b}}$ & $5.54 \pm 0.79^{\mathrm{b}}$ & $5.74 \pm 0.24^{\mathrm{b}}$ & $4.33 \pm 1.46^{\mathrm{b}}$ \\
5-caffeoylquinic acid/caffeine & $6.15 \pm 1.74^{\mathrm{a}}$ & $5.06 \pm 0.99^{\mathrm{a}}$ & $4.34 \pm 0.29^{\mathrm{a}}$ & $4.53 \pm 0.22^{\mathrm{a}}$ & $4.29 \pm 0.85^{\mathrm{a}}$ \\
\hline
\end{tabular}




\section{Discussion}

The coffee plants used for this experiment developed visual symptoms of cold stress as a result of low temperatures from October as indicated in Fig. 1. Characteristically, the coffee plants had pale yellow leaves and stunted growth, which is normally associated with low concentrations of Chls (Fig. 2). Foliar nitrogen sprays elevated the leaf nitrogen status to levels above $23 \mathrm{mg} \mathrm{g}^{-1}(\mathrm{DM})$ (Table 1), a threshold under which nitrogen-deficiency symptoms are reported to occur in coffee plants (Pompelli et al. 2010). The control plants on the other hand, were still $\mathrm{N}$-deficient at the end of the experiment and consequently accumulated lesser amounts of Chls and carotenoid pigments compared to the nitrogen supplied plants whose pigment concentration increased by 75 and $54 \%$, respectively, with increasing nitrogen concentration up to $20 \mathrm{mM}$ (Table 1). Low nitrogen nutrition generally results in low contents of both Chls and carotenoids, with the pigments increasing by over 135 and $125 \%$, respectively, when coffee plants were fertilized with $23 \mathrm{mM} \mathrm{N}$ twice every after two weeks (Pompelli et al. 2010). Nevertheless, in this study, the high nitrogen concentration of the $40 \mathrm{mM}$ treatment was associated with a remarked reduction in the concentration of the pigments. This is plausibly due to the burning effect associated with high concentration of foliar urea sprays. The negative effects of high concentration urea application on plant metabolism has been reported to result from accumulation of urea in plant tissues to toxic levels rather than its conversion to toxic substrates such as ammonia (Krogmeier et al. 1989). Therefore, at $40 \mathrm{mM}$, urea application was above the threshold and therefore its toxicity supressed plant metabolism although no burns were visually observed. Nonetheless, nitrogen supply in an appropriate concentration from foliar urea can be readily assimilated through combining with carbonyl chains form carbohydrates to form proteins and other important molecules such as Chls and carotenoids (Carelli et al. 2006, Pompelli et al. 2010) similar to observations made in the current study.

The low contents of photosynthetic pigments in the control plants were associated with low rates of gas exchange (Fig. 3). The seedlings used in the current study had been raised under a shaded vinyl house with irradiance levels similar to those used in the growth chamber (PPFD of $\left.250 \mu \mathrm{mol} \mathrm{m} \mathrm{m}^{-2} \mathrm{~s}^{-1}\right)$. The current results agree with Praxedes et al. (2006) and Pompelli et al. (2010) who reported low net $\mathrm{CO}_{2}$ assimilation in plants with low concentration of nitrogen and photosynthetic pigments. Chls play a vital role in both absorption and conversion of sunlight energy into chemical energy. In the current study, a consistent increase in the Chl concentration in the nitrogen-treated plants was accompanied with high rates of $\mathrm{CO}_{2}$ assimilation (Fig. $3 A$ ). Stomatal conductance also tended to be the highest in plants with high $\mathrm{CO}_{2}$ assimilation rates suggesting a positive effect of the improved water status in the coffee plants as a result of foliar nitrogen treatment on photosynthesis in general (Gimenez et al. 2005). Moreover, compared with control plants, nitrogen treatment improved $\mathrm{WUE}_{\mathrm{i}}$, indicating a higher biomass gain per unit water loss that occurs through transpiration (Hatfield and Dold 2019). Control plants also indicated the highest $C_{\mathrm{i}} / C_{\mathrm{a}}$ ratio compared to nitrogen-treated plants (Fig. $3 D$ ). This was possibly due to the inability of the mesophyll cells to assimilate the absorbed $\mathrm{CO}_{2}$ in the intercellular air spaces (Farquhar et al. 1980). This phenomenon could have been induced by several biochemical limitations such as low photosynthetic enzymatic activities that were greatly improved by foliar nitrogen concentrations of up to $20 \mathrm{mM}$ (Sun et al. 2016). On the other hand, plants under $40 \mathrm{mM}$ had low rates of gas exchange (Fig. 3), empathizing the negative effects caused by high nitrogen concentration in this treatment. Similar results were obtained in coffee plants under conventional nitrogen supply (Bote et al. 2018) and in apple trees where plants grown under adequate nitrogen supply maintained higher photosynthetic rates even at low temperatures compared to those growing under soil nitrogen deficient conditions (Greer 2018).

The trend in the $\mathrm{CO}_{2}$ assimilation rate was further supported by corresponding variations in the PSII photochemistry (Table 3 ). Both $\Phi_{\text {PSII }}$ and ETR showed similar quadratic variation amongst the treatments being lowerin the both control and $40 \mathrm{mM}$ plants whereas low concentration nitrogen-treated plants had moderate values. The current results suggest therefore that the PSII photochemical efficiency during steady-state photosynthesis tended to be downregulated in the photosynthetically depressed plants as a mechanism of photoprotection, which would otherwise result into photoinhibition due to an inefficient photosynthetic apparatus (Maxwell and Johnson 2000, Murchie and Lawson 2013). Moreover, control plants had both the highest $\mathrm{q}_{\mathrm{P}}$ and NPQ with the two parameters declining with increasing concentrations in the nitrogen treatments (Table 3 ). Nonetheless, a slight increase in the NPQ in plants under $40 \mathrm{mM}$ indicated plausible damages to the photosynthetic apparatus resulting from the toxicity of the urea application in high concentrations. Moreover, plants under control and $40 \mathrm{mM}$ treatments tended to close larger proportions of the PSII traps which otherwise could have caused photoinhibition due to biochemical limitations for high photosynthetic rates (Table 3 ). On the contrary, plants under moderate nitrogen concentration treatments had higher $\mathrm{q}_{\mathrm{L}}$ hence facilitating the flow of electrons from PSI to PSII, which resulted into higher photosynthetic rates (Murchie and Lawson 2013).

The maximum quantum efficiency of PSII under both dark and light conditions was also the lowest in the control and $40 \mathrm{mM}$-treated plants (Fig. 4). Both $F_{v} / F_{m}$ and $F_{v} / F_{0}$ for both the dark- and the light-adapted states $\left(\mathrm{F}_{\mathrm{v}}{ }^{\prime} / \mathrm{F}_{\mathrm{m}}{ }^{\prime}\right.$ and $\left.\mathrm{F}_{\mathrm{v}}{ }^{\prime} / \mathrm{F}_{0}{ }^{\prime}\right)$ are indicators of the degree of photoinhibition in PSII (Adams et al. 1995, Maxwell and Johnson 2000, Demmig-Adams and Adams 2006). The current results agree with Pompelli et al. (2010) who also reported lower $\mathrm{F}_{\mathrm{v}} / \mathrm{F}_{\mathrm{m}}$ ratio in low- $\mathrm{N}$ coffee plants especially under high-light conditions. Such low $\mathrm{F}_{\mathrm{v}} / \mathrm{F}_{\mathrm{m}}$ ratios have also been reported in coffee plants after exposure to cold stress conditions (Guo and Cao 2004, Batista-Santos et al. 2011). This decline in the maximum quantum efficiency is attributed to downregulation of PSII due to photoprotec- 
tive energy dissipation, which is associated with nocturnal retention, and diurnal build-up of zeaxanthin in the xanthophyll cycle (Verhoeven et al. 1997, Ramalho et al. 2003, Partelli et al. 2009, Pompelli et al. 2010, BatistaSantos et al. 2011). This defence mechanism is, however, associated with inactive reaction centres and competes for energy with PSII photochemistry hence reducing its photochemical efficiency (Partelli et al. 2009).

The current results also indicated that in absence of an efficient photosynthetic system such as in control treatment plants, coffee plants accumulate relatively higher amounts of the secondary metabolites except caffeine (Table 3). Coffee plants contain two main alkaloids compounds whose roles in antioxidant defence are still unknown (Ashihara 2006). Accumulation of caffeine has been more associated with defence against herbivory, whereas trigonelline accumulates as a consequence of detoxification of nicotinic acid, a reservoir for biosynthesis of nicotinamide adenine dinucleotide (Shimizu and Mazzafera 2000). High contents of trigonelline [up to $0.61 \mathrm{mg} \mathrm{g}^{-1}(\mathrm{DM})$ ] in the control plants compared to other treatments were observed in the current study. This is in consistence with Garg (2016) who recently indicated that trigonelline may have antioxidant roles in plant cells.

The main hydroxycinnamic acid ester, 5-CQA (Campa et al. 2012), and the xanthonoid, mangiferin, were also in the highest amounts in the control plants and decreased in the nitrogen-supplied plants (Table 3 ). The two phenolic compounds have been found to increase directly in response to oxidative stresses induced by high light intensities and cold stress conditions to which the coffee plant is not adapted to (Ramalho et al. 2014, Campa et al. 2017, Acidri et al. 2020a). The current results indicated a higher ratio of 5-CQA to caffeine in the photosynthetically limited plants compared to those treated with foliar sprays of nitrogen (Table 3). Chlorogenic acids such as 5-CQA have a higher metabolic plasticity compared to caffeine and act as storage forms of cinnamic acid derivatives which are used for lignification during cell wall development (Aerts and Baumann 1994). Therefore, the decline in the 5-CQA concentration could be attributed to a higher need for cell wall development than for defence against ROS in plants whose photosynthetic apparatus had been recovered by foliar nitrogen treatment. Yildirim et al. (2007) also observed a decline in ascorbic acid, a wellknown antioxidant compound in nitrogen-treated broccoli plants compared to those under control conditions.

Nonenzymatic antioxidant compounds, such as phenolics, carotenoids, ascorbic acid, tocopherols and alkaloids, contain electrophilic carboxylic linkages and hydroxyl components, which neutralise the excess ROS generated during oxidative stress conditions (Das and Roychoudhury 2014). The presence of high contents of the secondary metabolites in the control treatment could therefore be due to the inability of the coffee plants to recover their photosynthetic apparatus in absence of foliar nitrogen sprays as indicated by contracted photosynthetic efficiency. On the other hand, the low photosynthetic rates in the high concentration foliar treatment, especially $40 \mathrm{mM}$, did not result in high antioxidant content possibly due to accumulation of urea to toxic concentrations thereby supressing pigments and secondary metabolism in the leaves of the coffee plants (Krogmeier et al. 1989).

Conclusion: Foliar supply of different nitrogen concentrations $(0,5,10,20$, and $40 \mathrm{mM})$ variably affected the recovery of both photosynthetic apparatus and its efficiency in the leaves of coffee seedlings with $10 \mathrm{mM}$ causing the most significant effect. This recovery was associated with improved leaf nitrogen status and concentration of the photosynthetic pigments. On the contrary, nitrogen nutrition in the foliar urea sprays was associated with low concentrations of both alkaloids and phenolic compounds such as trigonelline and 5-CQA, respectively. Therefore, foliar urea supply containing $10 \mathrm{mM}$ nitrogen was appropriate in recuperating the photosynthetic apparatus and hence enhanced the recovery of the photosynthetic performance of the previously cold-stressed coffee seedlings.

\section{References}

Acidri R., Sawai Y., Sugimoto Y. et al.: Exogenous kinetin promotes the nonenzymatic antioxidant system and photosynthetic activity of coffee (Coffea arabica L.) plants under cold stress conditions. - Plants-Basel 9: 281, 2020a.

Acidri R., Sawai Y., Sugimoto Y. et al.: Phytochemical profile and antioxidant capacity of coffee plant organs compared to green and roasted coffee beans. - Antioxidants-Basel 9: 93, 2020b.

Adams III W.W., Demmig-Adams B., Verhoeven A.S., Barker D.H.: 'Photoinhibition' during winter stress: involvement of sustained xanthophyll cycle-dependent energy dissipation. Funct. Plant Biol. 22: 261-276, 1995.

Adams III W.W., Zarter C.R., Ebbert V., Demmig-Adams B.: Photoprotective strategies of overwintering evergreens. Bioscience 54: 41-49, 2004.

Aerts R.J., Baumann T.W.: Distribution and utilization of chlorogenic acid in Coffea seedlings. - J. Exp. Bot. 45: 497503, 1994.

Asada K.: The water-water cycle in chloroplasts: Scavenging of active oxygens and dissipation of excess photons. - Annu. Rev. Plant Phys. 50: 601-639, 1999.

Asada K: Production and scavenging of reactive oxygen species in chloroplasts and their functions. - Plant Physiol. 141: 391-396, 2006.

Ashihara H.: Metabolism of alkaloids in coffee plants. - Braz. J. Plant Physiol. 18: 1-8, 2006.

Batista-Santos P., Lidon F.C., Fortunato A. et al:: The impact of cold on photosynthesis in genotypes of Coffea spp. photosystem sensitivity, photoprotective mechanisms and gene expression. - J. Plant Physiol. 168: 792-806, 2011.

Bhuyan M.H.M., Ferdousi M.R., Iqbal M.T.: Foliar spray of nitrogen fertilizer on raised bed increases yield of transplanted aman rice over conventional method. - ISRN Agronomy 2012: 184953, 2012.

Bote A.D., Zana Z., Ocho F.L., Vos J.: Analysis of coffee (Coffea arabica $\mathrm{L}$.) performance in relation to radiation level and rate of nitrogen supply II. Uptake and distribution of nitrogen, leaf photosynthesis and first bean yields. - Eur. J. Agron. 92: 107-114, 2018.

Campa C., Mondolot L., Rakotondravao A. et al.: A survey of mangiferin and hydroxycinnamic acid ester accumulation in coffee (Coffea) leaves: biological implications and uses. - 
Ann. Bot.-London 110: 595-613, 2012.

Campa C., Urban L., Mondolot L. et al.: Juvenile coffee leaves acclimated to low light are unable to cope with a moderate light increase. - Front. Plant Sci. 8: 1126, 2017.

Carelli M.L.C., Fahl J.I. Ramalho J.D.C.: Aspects of nitrogen metabolism in coffee plants. - Braz. J. Plant Physiol. 18: 9-21, 2006.

Charrier A., Berthaud J.: Botanical classification of coffee. In: Clifford M.N., Willson K.C. (ed.): Coffee: Botany, Biochemistry and Production of Beans and Beverage. Pp. 1347. Croom Helm, London-Sydney 1985.

Chaves A.R., Ten-Caten A., Pinheiro H.A. et al.: Seasonal changes in photoprotective mechanisms of leaves from shaded and unshaded field-grown coffee (Coffea arabica L.) trees. - Trees 22: 351, 2008.

DaMatta F.M.: Ecophysiological constraints on the production of shaded and unshaded coffee: a review. - Field Crop. Res. 86: 99-114, 2004.

DaMatta F.M., do Amaral J.A., Rena A.B.: Growth periodicity in trees of Coffea arabica L. in relation to nitrogen supply and nitrate reductase activity. - Field Crop. Res. 60: 223-229, 1999.

DaMatta F.M., Loos R.A., Silva E.A. et al.: Effects of soil water deficit and nitrogen nutrition on water relations and photosynthesis of pot-grown Coffea canephora Pierre. Trees 16: 555-558, 2002.

DaMatta F.M., Maestri M., Mosquim P.R., Barros R.S.: Photosynthesis in coffee (Coffea arabica and C. canephora) as affected by winter and summer conditions. - Plant Sci. 128: 43-50, 1997.

DaMatta F.M., Ramalho J.C.: Impacts of drought and temperature stress on coffee physiology and production: a review. - Braz. J. Plant Physiol. 18: 55-81, 2006.

Das K., Roychoudhury A.: Reactive oxygen species (ROS) and response of antioxidants as ROS-scavengers during environmental stress in plants. - Front. Env. Sci. 2: 53, 2014.

del Río L.A., Corpas F.J., Sandalio L.M. et al.: Reactive oxygen species, antioxidant systems and nitric oxide in peroxisomes. - J. Exp. Bot. 53: 1255-1272, 2002.

Demmig-Adams B., Adams III W.W.: Photoprotection in an ecological context: the remarkable complexity of thermal energy dissipation. - New Phytol. 172: 11-21, 2006.

Fageria N.K., Filho M.B., Moreira A. et al.: Foliar fertilization of crop plants. - J. Plant Nutr. 32: 1044-1064, 2009.

Farquhar G.D., von Caemmerer S.V., Berry J.A.: A biochemical model of photosynthetic $\mathrm{CO}_{2}$ assimilation in leaves of $\mathrm{C}_{3}$ species. - Planta 149: 78-90, 1980.

Fortunato A.S., Lidon F.C., Batista-Santos P. et al.: Biochemical and molecular characterization of the antioxidative system of Coffea sp. under cold conditions in genotypes with contrasting tolerance. - J. Plant Physiol. 167: 333-342, 2010.

Garg S.K.: Green coffee bean. - In: Gupta R.C. (ed.): Nutraceuticals: Efficacy, Safety and Toxicity. Pp. 653-667. Academic Press, London 2016.

Gebreselassie W., Mohammed A., Netsere A.: Pre-sowing treatment of coffee (Coffea arabica L.) seeds to enhance emergence and subsequent growth of seedlings. - Res. J. Seed Sci. 3: 218-226, 2010.

Gimenez C., Gallardo M., Thompson R.B.: Plant-water relations. - In: Hillel D. (ed.): Encyclopedia of Soils in the Environment. Pp. 231-238. Amsterdam, Elsevier 2005.

Gray R.C., Akin G.W.: Foliar fertilization. - In: Hauck R.D. (ed.): Nitrogen in Crop Production. Pp. 579-584. ASA, Madison 1984.

Greer D.H.: Photosynthetic responses to $\mathrm{CO}_{2}$ at different leaf temperatures in leaves of apple trees (Malus domestica) grown in orchard conditions with different levels of soil nitrogen. Environ. Exp. Bot. 155: 56-65, 2018.

Guo Y.H., Cao K.F.: Effect of night chilling on photosynthesis of two coffee species grown under different irradiances. J. Hortic. Sci. Biotech. 79: 713-716, 2004.

Hatfield J.L., Dold C.: Water-use efficiency: advances and challenges in a changing climate. - Front. Plant Sci. 10: 103, 2019.

Hoagland D.C., Arnon D.I.: The Water Culture Method for Growing Plant Without Soil. Pp. 32. California Agricultural Experiment Station, Berkeley 1950.

Krogmeier M.J., McCarty G.W., Bremner J.M.: Phytotoxicity of foliar-applied urea. - P. Natl. Acad. Sci. USA 86: 8189-8191, 1989.

Lichtenthaler H.K., Buschmann C.: Chlorophylls and carotenoids: measurement and characterization by UV-VIS spectroscopy.Curr. Protoc. Food Anal. Chem. 1: F4.3.1-F4.3.8, 2001.

Liu Z., Tao L., Liu T. et al.: Nitrogen application after lowtemperature exposure alleviates tiller decrease in rice. Environ. Exp. Bot. 158: 205-214, 2019.

Logan B.A., Kornyeyev D., Hardison J., Scott Holaday A.: The role of antioxidant enzymes in photoprotection. - Photosynth. Res. 88: 119-132, 2006.

Matos F.S., Wolfgramm R., Gonçalves F.V. et al.: Phenotypic plasticity in response to light in the coffee tree. - Environ. Exp. Bot. 67: 421-427, 2009.

Maxwell K., Johnson G.N.: Chlorophyll fluorescence a practical guide. - J. Exp. Bot. 51: 659-668, 2000.

Mittler R.: Oxidative stress, antioxidants and stress tolerance. Trends Plant Sci. 7: 405-410, 2002.

Murchie E.H., Lawson T.: Chlorophyll fluorescence analysis: a guide to good practice and understanding some new applications. - J. Exp. Bot. 64: 3983-3998, 2013.

Oad R.K., Ansari M.A., Kumar J., Menghwar D.R.: Effect of foliar applied urea on growth and yield of sunflower (Helianthus annuus L.). - Open Access Library J. 5: e4668, 2018.

Partelli F.L., Vieira H.D., Viana A.P. et al.: Low temperature impact on photosynthetic parameters of coffee genotypes. Pesqui. Agropecu. Bras. 44: 1404-1415, 2009.

Pompelli M.F., Martins S.C., Antunes W.C. et al.: Photosynthesis and photoprotection in coffee leaves is affected by nitrogen and light availabilities in winter conditions. - J. Plant Physiol. 167: 1052-1060, 2010.

Porra R.J., Thompson W.A., Kriedemann P.E.: Determination of accurate extinction coefficients and simultaneous equations for assaying chlorophylls $a$ and $b$ extracted with four different solvents: verification of the concentration of chlorophyll standards by atomic absorption spectroscopy. - BBABioenergetics 975: 384-394, 1989.

Praxedes S.C., DaMatta F.M., Loureiro M.E. et al: Effects of long-term soil drought on photosynthesis and carbohydrate metabolism in mature robusta coffee (Coffea canephora Pierre var. kouillou) leaves. - Environ. Exp. Bot. 56: 263-273, 2006.

Ramalho J.C., DaMatta F.M., Rodrigues A.P. et al.: Cold impact and acclimation response of Coffea spp. plants. - Theor. Exp. Plant Phys. 26: 5-18, 2014.

Ramalho J.C., Pons T.L., Groeneveld H.W. et al.: Photosynthetic acclimation to high light conditions in mature leaves of Coffea arabica L.: role of xanthophylls, quenching mechanisms and nitrogen nutrition. - Funct. Plant Biol. 27: 43-51, 2000.

Ramalho J.C., Quartin V.L., Leitão E. et al.: Cold acclimation ability and photosynthesis among species of the tropical Coffea genus. - Plant Biol. 5: 631-641, 2003.

Ramalho J.C., Rodrigues A.P., Lidon F.C. et al.: Stress cross-response of the antioxidative system promoted by 
superimposed drought and cold conditions in Coffea spp. PLoS ONE 13: e0198694, 2018.

Shepherd M.F., Barzetti S., Hastie D.R.: The production of atmospheric $\mathrm{NO}_{\mathrm{x}}$ and $\mathrm{N}_{2} \mathrm{O}$ from a fertilized agricultural soil. Atmos. Environ. 25: 1961-1969, 1991.

Shimizu M.M., Mazzafera P.: A role for trigonelline during imbibition and germination of coffee seeds. - Plant Biol. 2: 605-611, 2000

Sun J., Ye M., Peng S., Li Y.: Nitrogen can improve the rapid response of photosynthesis to changing irradiance in rice
(Oryza sativa L.) plants. - Sci. Rep.-UK 6: 31305, 2016.

Verhoeven A.S., Demmig-Adams B., Adams III W.W.: Enhanced employment of the xanthophyll cycle and thermal energy dissipation in spinach exposed to high light and $\mathrm{N}$ stress. Plant Physiol. 113: 817-824, 1997.

Yildirim E., Guvenc I., Turan M., Karatas A.: Effect of foliar urea application on quality, growth, mineral uptake and yield of broccoli (Brassica oleracea L. var. italica). - Plant Soil Environ. 53: 120-128, 2007.

(C) The authors. This is an open access article distributed under the terms of the Creative Commons BY-NC-ND Licence. 